\title{
Dental arch Transversal characteristics in boys and girls with orthognathic bite: head shape and face type dependence
}

\author{
Igor Gunas $^{1 *}$, Alona GlushaK ${ }^{2}$, Andriy Samoylenko ${ }^{3}$
}

${ }^{1}$ International Academy of Integrative Anthropology

${ }^{2}$ Vinnitsa National Medical University named after Pirogov, Pirogov 56, Vinnitsa, Ukraine

${ }^{3}$ SI Dnepropetrovsk Medical Academy of the Ministry of Health of Ukraine»

\begin{tabular}{ll}
\hline $\begin{array}{l}\text { ARTICLE INFO } \\
\begin{array}{l}\text { Received 23 January 2015 } \\
\text { Accepted 24 March 2015 }\end{array}\end{array}$ & $\begin{array}{l}\text { ABSTRACT } \\
\text { In this work, we describe the boundary percentile scope values oftransversalcharacteristics } \\
\text { of the dental arch of boys and girls of Podillia, with diagnosed orthognathic bite. The } \\
\text { study group consists of individuals with different forms of head and face. Our findings } \\
\begin{array}{l}\text { Keywords: } \\
\text { teenagers, } \\
\text { head shape, } \\
\text { face type, } \\
\begin{array}{l}\text { orthognathic bite, } \\
\text { transversal dental arch } \\
\text { characteristics, } \\
\text { sexual differences. }\end{array}\end{array} \\
\begin{array}{l}\text { upper and lower jaw, both in the distribution of the shape of the head, and the type of } \\
\text { face. In boys with different head shape, larger values of transversal size of dental arch are } \\
\text { evidenced when contrasted with the corresponding groups of girls, regarding the maxilla }\end{array} \\
\text { in } 46.7 \% \text { of all cases and the mandible in } 22.2 \% \text { of all cases, as well as with different types } \\
\text { of faces in } 66.7 \% \text { of cases regarding the maxilla and } 55.6 \% \text { in the mandible. }\end{array}$ \\
\hline
\end{tabular}

\section{INTRODUCTION}

The dental arch, in general, forms a functional system displaying a unity and a stability which fixes the teeth in the sense of the orientation of their crowns and roots [1]. However, literature suggests that the alveolar and palatal processes which belong to the structures of the facial skull and form the upper dental arch, in adolescence, undergo significant changes regarding their shape, their parameters (transversal dimensions of the upper dental arch) and their relationships with other structures. These changes result from the final synostosis of the palatal seams, and increase in width with regard to the alveolar process, at the level of the first big molar tooth $[2,8]$.

It should be noted that during evolution, the progressive development of the brain influenced both the growth of the brain skull, and the growth of individual elements of the facial skeleton (mainly in the frontal and sagittal planes), giving rise to their smaller size at the dolichocephalic, and, vice versa, their greater their size at the brachycephalic $[9,10]$. This fact shows that, in essence, the facial skeleton is an integrated dynamic system which has a distinctive identity that had formed and developed in close relationship with the shape and size of brain department (craniotypes). Hence, such a notion should be considered when studying the transversal characteristics of the tooth arc.

\footnotetext{
* Corresponding author

e-mail: igor.gunas@mail.ru;

tel.: 067-1210005
}

\section{MATERIALS AND METHODS}

The primary indicator of the size of the teeth and head shapes and sizes of boys and girls of Podillia with orthognathic bite has been established by way of the Pirogov database SRC VNMU. For this, a comprehensive survey was conducted which involved 1158 urban girls of ages ranging from 12 to 15 years, and boys aged from 13 to 16 years. Of these, this study selected 243 girls and boys (all third generation residents of Podilsky region of Ukraine), by way of a preliminary visual inspection. From this sample population, fingerprints were taken, and orthodontic diagnostic gypsum models made of their upper and lower jaws. For the further study, we then selected out teenagers with orthognathic bite who had met the criteria as defined by the 11 points set by Bushan et al. [4]. As a result, the final cephalometric study group consisted of 49 boys and 48 girls. Of note, the Committee of Bioethics of Pirogov VNMU found that the studies are not contrary to the fundamental bioethical standards of the Helsinki Declaration, the European Convention on Human Rights and Biomedicine (1977), the relevant provisions of the WHO and the laws of Ukraine (protocol number 1 of 23.09.2003).

Within this study group, in the transversal plane, we measured the following parameters of maxillary dental arch: SHZR $3{ }_{2} 2-2^{\text {nd }}$ line size between the $13^{\text {th }}$ and $23^{\text {th }}$ teeth (the distance between the tops of canines); SHZR $4 \_3-3^{\text {rd }}$ linear dimension between the $14^{\text {th }}$ and $24^{\text {th }}$ teeth (distance between premolar points by Pon); SHZR $6 \_3-3^{\text {rd }}$ linear dimension between the $16^{\text {th }}$ and $26^{\text {th }}$ teeth (distance between 
molar points by Pon); and SDVIG_R, SDVIG_L - respectively, displacement of the $16^{\text {th }}$ or $26^{\text {th }}$ tooth relative to palatal suture (distance between the molar point by Pon and the central sagittal line). Similar linear dimensions were measured in the transversal plane for the mandible dental arch: SHZR $3 \mathrm{~N}$ - linear dimension between the tops of the $33^{\text {rd }}$ and $43^{\text {rd }}$ teeth; SHZR $4 \mathrm{~N}$ - linear dimension between the tops of the 34th and 44th teeth; and SHZR $6 \mathrm{~N}$ - linear dimension between the tops of near-buccal edge of the $36^{\text {th }}$ and $46^{\text {th }}$ teeth.

Head shape was determined by the formula ms_ms * 100/g_op, where ms_ms - maximum width of the head (occipital diameter); g_op - the maximum length of the head (the distance from glabella to opisthocranion) [11]. By way of this criteria, we established the following distribution: boys dolichocephalic -2 , boys mesaticephalic -13 , boys brachycephalic -17 , boys hyperbrachycephalic -17 ; girls dolichocephalic -1 , mesaticephalic girls -13 , girls brachycephalic - 16 , girls hyperbrachycephalic -18 .

The type of face was determined using the morphological index of Garson - the ratio of morphological face length (direct distance from nasion to gnathion) to the width of the face in the area of the zygomatic arches [11]. By way of this criteria, we established the following distribution: boys with a very broad face -11 , boys with a broad face -20 , boys with a mean face -13 , boys with a narrow face -4 , boys with very narrow face -1 ; girls with a very broad face -15 , girls with a wide face -15 , girls with an average face -14 , girls with a narrow face -4 .

Statistical analysis of the results was performed using the statistical software package "Statistica 5.5" (belonging to the Piogov VNMU, license number AXXR910A374605FA) using nonparametric methods for assessing the results.

\section{RESULTS AND DISCUSSION}

The physiological dental arch forms associated with three constitutional types of face are seen in Figure 1. These are: dolichocephalic type (narrow face), mesaticephalic type (the average face) and brachycephalic type (wide face) [1]. The type of face, to some extent, has an effect upon the shaping of the dental arches and the alveolar processes (Fig. 1). According to Syemonov E. [7], in people with dolichocephalic, narrow and high faces, the arch of the palate bone is tall and narrow in its base (the width of palatal arch), while in persons with brachycephalic and broad faces - this is more flat and wide in the base.

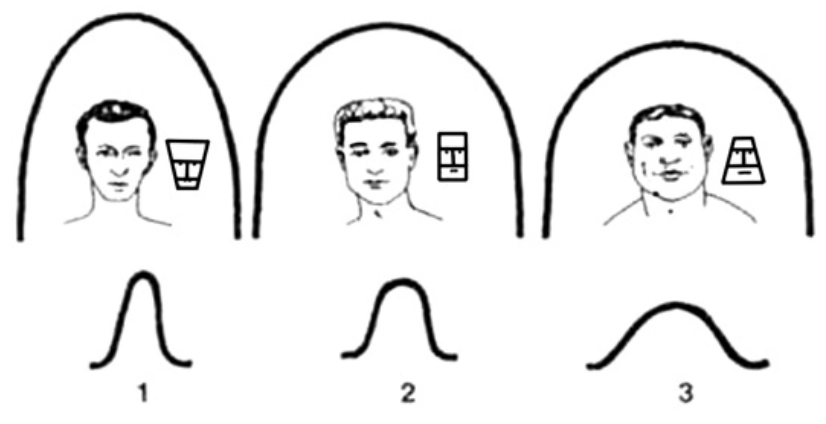

Figure 1. The shape of the face, dental arches and cross section of the alveolar processes: 1 - dolichocephalic, 2 - mesaticephalic 3 - brachycephalic (Abolmasov, 2008)

Our results indicate a set limit of Percentile scope (the 25,0 percentile and 75,0 percentile) with regard to the sizes of transversal characteristics of the dental arch in boys and girls with orthognathic bite, according to the shape of the head and the face type (Table. 1-2).

Table 1. Percentile scope transversal dimensions of the upper and lower jaw in boys and girls with different craniotypes (mm)

\begin{tabular}{|c|c|c|c|c|c|c|c|c|}
\hline \multirow{3}{*}{ Indicators } & \multicolumn{8}{|c|}{ Boys } \\
\hline & \multicolumn{2}{|c|}{ in general } & \multicolumn{2}{|c|}{ mesaticephalic } & \multicolumn{2}{|c|}{ brachycephalic } & \multicolumn{2}{|c|}{ hyperbrachycephalic } \\
\hline & $\begin{array}{l}\text { 25.0th } \\
\text { percentl }\end{array}$ & $\begin{array}{l}75,0 \text { th } \\
\text { percentl }\end{array}$ & $\begin{array}{l}25,0 \text { th } \\
\text { percentl }\end{array}$ & $\begin{array}{l}75,0 \text { th } \\
\text { percentl }\end{array}$ & $\begin{array}{l}25,0 \text { th } \\
\text { percentl }\end{array}$ & $\begin{array}{l}75,0 \text { th } \\
\text { percentl }\end{array}$ & $\begin{array}{l}25,0 \text { th } \\
\text { percentl }\end{array}$ & $\begin{array}{l}75,0 \text { th } \\
\text { percentl }\end{array}$ \\
\hline SHZR_3_2 & 34.2 & 36.2 & 34.5 & 36.9 & 34.2 & 35.7 & 34.1 & 36.0 \\
\hline SHZR_4_3 & 36.3 & 38.5 & 36.2 & 39.2 & 36.4 & 37.5 & 36.3 & 38.4 \\
\hline SHZR_6_3 & 48.5 & 51.3 & 49.0 & 51.3 & 48.4 & 51.0 & 48.5 & 51.5 \\
\hline SDVIG_R & 23.2 & 24.8 & 23.7 & 24.9 & 23.2 & 24.4 & 22.9 & 24.6 \\
\hline SDVIG_L & 23.7 & 24.8 & 23.0 & 24.6 & 23.7 & 24.4 & 24.0 & 25.1 \\
\hline SHZR_3N & 25.6 & 27.1 & 26.1 & 27.4 & 25.3 & 26.6 & 25.4 & 27.2 \\
\hline SHZR_4N & 34.3 & 35.9 & 34.9 & 36.0 & 34.0 & 35.1 & 34.3 & 35.8 \\
\hline SHZR_6N & 45.4 & 48.0 & 45.1 & 49.3 & 45.5 & 47.1 & 45.3 & 47.6 \\
\hline \multirow{3}{*}{ Indicators } & \multicolumn{8}{|c|}{ Girls } \\
\hline & \multicolumn{2}{|c|}{ in general } & \multicolumn{2}{|c|}{ mesaticephalic } & \multicolumn{2}{|c|}{ brachycephalic } & \multicolumn{2}{|c|}{ hyperbrachycephalic } \\
\hline & $\begin{array}{c}25,0 \text { th } \\
\text { percentl }\end{array}$ & $\begin{array}{c}75,0 \text { th } \\
\text { percentl }\end{array}$ & $\begin{array}{c}25,0 \text { th } \\
\text { percentl }\end{array}$ & $\begin{array}{c}75,0 \text { th } \\
\text { percentl }\end{array}$ & $\begin{array}{c}25,0 \text { th } \\
\text { percentl }\end{array}$ & $\begin{array}{l}75,0 \text { th } \\
\text { percentl }\end{array}$ & $\begin{array}{l}25,0 \text { th } \\
\text { percentl }\end{array}$ & $\begin{array}{c}75,0 \text { th } \\
\text { percentl }\end{array}$ \\
\hline SHZR_3_2 & 32.5 & 34.5 & 33.5 & 34.7 & 32.2 & 34.6 & 32.6 & 34.2 \\
\hline SHZR_4_3 & 34.3 & 37.0 & 35.4 & 36.8 & 33.9 & 36.4 & 35.2 & 37.4 \\
\hline SHZR_6_3 & 46.0 & 48.6 & 46.6 & 49.1 & 45.8 & 47.8 & 46.1 & 49.0 \\
\hline SDVIG_R & 21.8 & 23.8 & 22.9 & 23.7 & 21.3 & 23.1 & 22.5 & 23.9 \\
\hline SDVIG_L & 22.3 & 24.1 & 23.1 & 23.8 & 21.0 & 23.4 & 22.7 & 25.0 \\
\hline SHZR_3N & 24.6 & 26.7 & 25.3 & 26.6 & 24.6 & 26.2 & 24.6 & 26.9 \\
\hline SHZR_4N & 32.4 & 35.4 & 32.8 & 35.4 & 32.0 & 34.5 & 33.0 & 35.5 \\
\hline SHZR_6N & 42.9 & 46.0 & 43.4 & 46.4 & 42.9 & 44.6 & 43.9 & 45.9 \\
\hline
\end{tabular}


Table 2. Percentile scope transversal dimensions of the upper and lower jaw in boys and girls with different types of face $(\mathrm{mm})$

\begin{tabular}{|c|c|c|c|c|c|c|}
\hline \multirow{3}{*}{ Indicators } & \multicolumn{6}{|c|}{ Boys } \\
\hline & \multicolumn{2}{|c|}{ very wide face } & \multicolumn{2}{|c|}{ broad face } & \multicolumn{2}{|c|}{ average face } \\
\hline & \begin{tabular}{|c|}
25,0 th \\
percentl
\end{tabular} & $\begin{array}{c}\text { 75,0th } \\
\text { percent| }\end{array}$ & $\begin{array}{c}25,0 \text { th } \\
\text { percent| }\end{array}$ & $\begin{array}{c}75,0 \text { th } \\
\text { percent }\end{array}$ & $\begin{array}{c}25,0 \text { th } \\
\text { percentl }\end{array}$ & $\begin{array}{c}75,0 \text { th } \\
\text { percent| }\end{array}$ \\
\hline SHZR_3_2 & 34.0 & 36.5 & 34.1 & 36.0 & 34.2 & 36.2 \\
\hline SHZR_4_3 & 36.3 & 38.5 & 36.2 & 38.5 & 36.2 & 38.2 \\
\hline SHZR_6_3 & 48.6 & 50.1 & 48.1 & 51.3 & 48.4 & 51.4 \\
\hline SDVIG_R & 23.0 & 24.3 & 23.0 & 24.9 & 23.3 & 24.8 \\
\hline SDVIG_L & 23.6 & 24.3 & 23.3 & 25.1 & 23.7 & 24.6 \\
\hline SHZR_3N & 25.5 & 27.2 & 25.3 & 26.6 & 25.7 & 27.0 \\
\hline SHZR_4N & 34.3 & 35.6 & 33.9 & 35.9 & 34.1 & 36.4 \\
\hline SHZR_6N & 45.5 & 47.6 & 44.6 & 47.6 & 45.3 & 49.2 \\
\hline \multirow{3}{*}{ Indicators } & \multicolumn{6}{|c|}{ Girls } \\
\hline & \multicolumn{2}{|c|}{ very wide face } & \multicolumn{2}{|c|}{ broad face } & \multicolumn{2}{|c|}{ average face } \\
\hline & \begin{tabular}{|c|}
25,0 th \\
percentl
\end{tabular} & $\begin{array}{c}75,0 \text { th } \\
\text { percent| }\end{array}$ & \begin{tabular}{|c|}
25,0 th \\
percentl
\end{tabular} & $\begin{array}{c}75,0 \text { th } \\
\text { percent }\end{array}$ & \begin{tabular}{|c|}
25,0 th \\
percentl
\end{tabular} & $\begin{array}{c}75,0 \text { th } \\
\text { percentl }\end{array}$ \\
\hline SHZR_3_2 & 32.3 & 34.5 & 31.6 & 34.4 & 33.6 & 34.8 \\
\hline SHZR_4_3 & 34.2 & 37.3 & 33.8 & 37.3 & 35.6 & 37.0 \\
\hline SHZR_6_3 & 45.6 & 49.0 & 45.5 & 48.6 & 46.6 & 48.7 \\
\hline SDVIG_R & 21.5 & 23.9 & 31.3 & 23.0 & 22.9 & 13.8 \\
\hline SDVIG_L & 22.3 & 23.9 & 21.2 & 24.6 & 23.2 & 24.3 \\
\hline SHZR_3N & 24.6 & 26.6 & 24.0 & 26.9 & 25.3 & 26.2 \\
\hline SHZR_4N & 32.8 & 35.4 & 31.7 & 35.8 & 33.5 & 35.3 \\
\hline SHZR_6N & 41.0 & 45.9 & 41.6 & 45.1 & 44.5 & 46.3 \\
\hline
\end{tabular}

In girls, regarding the brachycephalic, statistically significant results were seen in the tendency towards smaller values with respect to the magnitude of the distance between molar points by Pon, in the displacement of the $16^{\text {th }}$ or $26^{\text {th }}$ tooth relative to the palatal suture, as well as in linear dimensions between the tops of the $34^{\text {th }}$ and $44^{\text {th }}$ teeth and between the tops of the near-buccal edge of the $36^{\text {th }}$ and $46^{\text {th }}$ teeth, when the hyperbrachycephalic and mesaticephalic are compared (in the last, this is only seen in the biasing of the 26-tooth relative to the palatal suture and in the linear size between the tops of the $34^{\text {th }}$ and $44^{\text {th }}$ teeth). In boys with different forms of head, statistically significant differences or trends in the transversal dimensions of the upper and lower jaw were not established.

In girls with a wide face, statistically significant results were seen in reduced values of the distance between the tops of canines, the distance between molar points by Pon, the displacement of the $16^{\text {th }}$ tooth relative to the palatal suture and the linear size between the tops of the near-buccal edge of the $36^{\text {th }}$ and $46^{\text {th }}$ teeth, when compared with girls of an average face. In boys with different types of faces, trends to differences of transversal dimensions of the upper and lower jaw were not established.

The work of Synemonov found partial confirmation in our study. In fact, the increase of transversal sizes of dental arch happened in the direction of the increasing value of the cranial index (dimensions in dolichocephalic $<$ brachycephalic dimensions and mesaticephalic $<$ dimensions hyperbrachycephalic) and in the increasing value of the Garson morphological index (dimensions in patients with a very broad face $<$ size in patients with a wide face $<$ size in patients with an average face $<$ size in patients with narrow face $<$ size in patients with a very narrow face). Probably this comes about because, in people with wide type of faces, the constitutionally thickness of the collar part of the alveolar process is larger, in comparison to other types of faces (Fig. 1). This results in the loss of inner space between premolar points [8].

In most cases, in boys, the values for the mesaticephalic and hyperbrachycephalic were statistically significantly different to that of girls, with regard to the transversal dimensions of the upper jaw (except for the displacement of the $16^{\text {th }}$ or $26^{\text {th }}$ tooth relative to the palatal suture in hyperbrachycephalic), and also in the linear size between tops of the near-buccal edge of the $36^{\text {th }}$ and $46^{\text {th }}$ teeth. Of note, in boys with a broad face and a very broad face, our results were particularly statistically significant and had a tendency to reveal larger values of transversal size of the upper (in all cases, in boys with a wide face) and lower jaw (mostly in boys with a very broad face) than in girls. In boys with an average face, however, this greater value was established only for the distance between the tops of canines, the distance between molar points by Pon, and for linear size between the tops of the near-buccal edge of the 36th and 46th teeth.

Thus, in adolescents (both boys and girls) with different forms of head and different types of face, there are pronounced sexual differences (higher values in boys) in the transversal size of the dental arch $(46.7 \%$ in the maxilla and $22.2 \%$ in the mandible with different form of the head; $66.7 \%$ in the maxilla and $55.6 \%$ in the mandible with different types of face). This coincides with data obtained by other researchers, whose results also show sexual dimorphism of the indices of the transversal size of the dental arch (higher values evident with regard to boys) $[3,5,6]$.

\section{CONCLUSIONS}

1. In girls of different head shape, with orthognathic bite, statistically significant differences or trends of differences in the transversal dimensions of the upper and lower jaw are established primarily for the distance between the molar point by Pon (the $26^{\text {th }}$ tooth) and the central sagittal line, as well as in the linear size between the tops of the near-buccal edge of the right and left lower first large molar teeth (the $36^{\text {th }}$ and $46^{\text {th }}$ teeth); and with different types of face - for the distance between the molar point by Pon (the $16^{\text {th }}$ tooth) and the central sagittal line, as well as in the distance between the tops of canines.

2. In boys of different head shape and different types of face, with orthognathic bite, statistically significant differences or trends differences in the transversal dimensions of the upper and lower jaw were practically not established.

3. Pronounced sex differences exist with regard to the transversal size of the dental arch: higher values being seen in boys with different head shape, regarding the maxilla - in $46.7 \%$ of all cases, and regarding the mandible, $22.2 \%$ of all cases; and with different types of faces in $66.7 \%$ of cases in the maxilla and $55.6 \%$ of all cases regarding the mandible. 


\section{REFERENCES}

1. Abolmasov N.G., Abolmasov N.N.: Orthodontics: Training allowance. MEDpress-iform, 424, 2008.

2. Antonova O.A.: Age anatomy and physiology. Higher Education, 2008.

3. Burris B.G., Harris E.F.: Maxillary arch size and shape in American black and whites. Angle Orthod., 70, 4, 2000.

4. Bhushan M.G. et al.: Handbook of orthodontics. Kartia Moldoveniaske, 488, 1990.

5. Dmitriev M.O., Gunas I.V., Kuhar I.D.: Geometrical parameters and structural features of the dental arch in adolescents of Podillya with orthognathic bite. Scientific Bulletin of the Uzhgorod University, $24,2005$.

6. Hassan N., Hosseinzadeh N., Reza S.: The dental arch form revisited. Angle Orthod., 71, 5, 2001.

7. Semenov E.K.: Surgical anatomy of the hard palate. Moscow, 25, 1970.

8. Smirnov V.G, Persin L.S.: Clinical anatomy of the facial skeleton. Medicine, 224, 2007.

9. Yablokov A.V., Yusufov A.G.: Evolutionary theory. High School, 1976.

10. Yordanov J.: Anthropology in dentistry. Sofia, 256, 1981.

11. Zubov A.A.: Odontology. Methods of anthropological research. Science, 198, 2003 